\title{
Studi dan Evaluasi Kayu sebagai Bahan Dasar Quadratic Residue Diffuser Akustik
}

\author{
Aditya Imam Wicaksono ${ }^{1}$, Fitria Hidayanti ${ }^{1}$, V. Vekky R. Repi ${ }^{1}$, Hari Hadi Santoso ${ }^{2}$ \\ ${ }^{1}$ Program Studi Teknik Fisika, Fakultas Teknik dan Sains, Universitas Nasional Jakarta \\ ${ }^{2}$ Pusat Penelitian Kalibrasi Instrumentasi Metrologi LIPI Serpong \\ Korespondensi: vekky_repi@yahoo.com
}

\begin{abstract}
ABSTRAK. Penelitian ini membahas tentang pengujian diffuser dengan menggunakan kayu-kayu yang berbeda (kayu tripleks meranti, kayu jati, dan kayu kamper). Tujuan pengujian ini adalah untuk memudahkan insinyur akustik memilih kayu yang akan digunakan sebagai diffuser dalam perancangan tata suara auditorium. Pengujian dilakukan dengan metode boundary plane measurement yang merujuk pada AES-4id-2001. Hasil pengujian diperoleh grafik respon polar dan koefisien difusi dengan frekuensi $800 \mathrm{~Hz}$, $1000 \mathrm{~Hz}$, dan $1250 \mathrm{~Hz}$. Berdasarkan pengujian tersebut, kayu kamper merupakan kayu yang terbaik untuk dijadikan diffuser.
\end{abstract}

Kata Kunci: Boundary Plane Measurement, Grafik Respon Polar, Kayu, Koefisien Difusi, Quadratic Residue Diffuser.

\section{PENDAHULUAN}

Peranan tata suara menjadi hal yang sangat penting pada bagian auditorium supaya informasi sampai kepada pendengar dan pendengar merasa nyaman ketika berada di auditorium. Berdasarkan hal tersebut, insinyur akustik merancang sistem tata suara yang baik dengan menggunakan perangkat sistem suara dan bahan akustik yang dapat memadukan suara-suara yang ada. Ketika perangkat sistem suara sudah baik namun kualitas suara yang didengar oleh pendengar belum baik maka bahan-bahan akustik digunakan untuk memperbaiki kualitas suara tersebut. Salah satu jenis bahan akustik yang digunakan adalah diffuser.

Diffuser merupakan sebuah konstruksi yang dapat menyebarkan suara pada arah yang berbeda dan sudah diketahui [1]. Diffuser umumnya dibuat dengan berbahan dasar kayu dengan bentukbentuk tertentu sesuai dengan jenis diffusernya. Tidak semua material kayu diffuser yang digunakan memiliki tingkat penyebaran suara yang seragam dan merata, karena setiap material memiliki tingkat penyerapan suara dan massa jenis yang berbeda [2]. Oleh karena itu, diperlukan pengujian diffuser untuk mengetahui kemampuan kayu diffuser dengan pendekatan akustik [3]. Pengujian yang digunakan pada penelitian ini adalah pengujian boundary plane measurement yang merujuk pada standar Audio Engineering Society nomor AES-4id-2001 tahun 2001[4].

\section{METODE PENELITIAN}

Bagian ini menerangkan metode yang digunakan pada penelitian ini. Bagian ini terdiri dari material kayu dan desain yang digunakan pada pembuatan diffuser, metode pengukuran dan metode pengolahan data yang disadur dari standar Audio Engineering Society nomor AES-4id2001 tahun 2001.

\section{Material Kayu dan Desain}

Kayu yang digunakan dalam penelitian ini adalah kayu tripleks meranti, kayu jati, dan kayu kamper. Spesifikasi jenis kayu dapat dilihat pada tabel 1.

TABEL 1. Spesifikasi Jenis Kayu.

\begin{tabular}{|l|c|c|c|}
\hline & Diffuser A & Diffuser B & Diffuser C \\
\hline Nama Umum & Meranti merah terang [5] & Jati[6] & Kamper[7] \\
\hline Nama Ilmiah & Shorea spp. & Tectona grandis & Cinnamomum champora \\
\hline Penyebaran Pohon & Asia Tenggara & Asia Tenggara & Asia Tenggara \\
\hline Specific Gravity (kadar air 12 \%) & $0.40,0.48$ & $0.55,0.66$ & $0.43,0.52$ \\
\hline
\end{tabular}


Pembuatan tiga diffuser menggunakan diffuser jenis Quadratic Residue Diffuser. Konstruksi Quadratic Residue Diffuser menggunakan serangkaian kolom dengan lebar kolom yang sama di tiap kolomnya yang dipisahkan oleh pemisah tipis [8]. Kedalaman tiap kolom dihitung dengan satu dari sejumlah urutan untuk memaksimalkan difusi pada bidang transversal terhadap kolomkolomnya [9]. Pembuatan diffuser tersebut melibatkan pengrajin mebel setempat. Penentuan ukuran diffuser disesuaikan dengan frekuensi desain dan frekuensi puncak diffuser. Frekuensi desain diffuser yang dibuat adalah $1000 \mathrm{~Hz}$ dan frekuensi puncak diffuser adalah 3400 Hz.Kedalaman kolom Quadratic Residue Diffuser yang dibuat dapat dilihat pada tabel 2.

TABEL 2. Ukuran Kedalaman Kolom.

\begin{tabular}{|c|c|c|c|}
\hline Kolom ke- & Bilangan (n) & $\begin{array}{c}\text { Faktor } \\
\text { Proporsional } \\
\text { kedalaman } \\
\text { kolom }\left(\mathbf{s}_{\mathbf{n}}\right)\end{array}$ & Kedalaman (mm) \\
\hline 1 & 0 & 0 & 0 \\
\hline 2 & 1 & 1 & 25 \\
\hline 3 & 2 & 4 & 100 \\
\hline 4 & 3 & 2 & 50 \\
\hline 5 & 4 & 2 & 50 \\
\hline 6 & 5 & 4 & 100 \\
\hline 7 & 6 & 1 & 25 \\
\hline
\end{tabular}

\section{Metode Pengukuran}

Salah satu metode pengujian diffuser adalah metode boundary plane measurement. Metode ini disadur dari AES-4id-2001 tentang karakterisasi dan pengukuran keseragaman penyebaran pada permukaan yang dibuat oleh Audio Engineering Society, Inc. (AES) pada tahun 2001 [4]. Dokumen tersebut memberikan panduan untuk meng-karakterisasi keseragaman penyebaran yang dihasilkan oleh diffuser terhadap pengukuran atau prediksi penyebaran respon polar. Dalam konteks tersebut, penyebaran suara terhadap permukaan dinilai dengan koefisien difusi tunggal.

Pengujian ini dilakukan dengan cara menempatkan diffuser yang dikelilingi oleh barisan mikrofon. Mikrofon-mikrofon ditempatkan pada posisi-posisi sesuai sudut-sudut pantulan diffuser tersebut dengan jarak yang sama antara diffuser dan masing-masing mikrofon. Sedangkan pengeras suara ditempatkan di luar barisan mikrofon. Suara dengan frekuensi tertentu 'ditembakkan' menuju sampel diffuser, kemudian diffuser memantulkan ke pelbagai arah. Selanjutnya, mikrofon merekam suara pantulan diffuser dan suara pengeras suara di tiap posisi mikrofon yang sudah diketahui sudut penerimaannya. Gambar 1 merupakan penerapan pengujian yang dilakukan.

Penerapan pengujian menggunakan beberapa peralatan seperti mikrofon, pengeras suara, dan perlengkapan pendukung audio lainnya [10]. Pengeras suara diletakkan berhadapan langsung dengan diffuser dan memberikan suara gelombang sinus dengan frekuensi $800 \mathrm{~Hz}, 1000 \mathrm{~Hz}$, dan $1250 \mathrm{~Hz}$ menuju diffuser atau sampel. Pantulan suara diffuser akan direkam oleh mikrofon yang sudah ditentukan posisi penempatannya. Satu mikrofon diletakkan pada 19 posisi yang disebar mengelilingi diffuser dengan jarak $1.6 \mathrm{~m}$ dan dipindahkan ke posisi berikutnya secara bergantian setelah satu posisi mikrofon merekam frekuensi yang diuji [11]. 19 posisi berarti pengukuran dilakukan tiap 10 derajat terhadap diffuser.Pengeras suara diletakkan berhadapan dengan diffuser dengan jarak $1.9 \mathrm{~m}$. Mikrofon yang digunakan adalah mikrofon jenis kondenser dengan model Samson C02 [12]. Sedangkan pengeras suara yang digunakan adalah pengeras suara monitor dengan model Mackie CR-3 [13].

\section{Metode Perhitungan}

Pengolahan pengukuran bertujuan untuk mencari respon polar dan koefisien difusi pada satu diffuser. Gambar 2 merupakan gambaran umum pengolahan pengukurannya [4]. Gambar 2 bagian A merupakan proses perekaman pantulan diffuser yang dilakukan oleh mikrofon pada 
satu posisi sudut. Pada gambar 2 bagian B, hasil perekaman pantulan semua posisi sudut direkam pada perangkat lunak komputer yang ditampilkan dalam grafik rekaman dengan domain waktu. Rekaman mikrofon yang dibedakan antara rekaman pengeras suara dan rekaman pantulan diffuser. Pada gambar bagian $\mathrm{C}$, rekaman pantulan diffuser pada semua posisi sudut dimurnikan dengan teknik penyelisihan rekaman antara rekaman yang diukur dengan menggunakan diffuser dan rekaman yang diukur tanpa menggunakan diffuser. Kemudian, pada gambar bagian $\mathrm{D}$, rekaman pantulan diffuser yang sudah dimurnikan diubah dari domain waktu menjadi domain frekuensi untuk mencari intensitas pantulan setiap sudut dan dibuat grafik respon polar. Grafik respon polar dibuat dengan pengambilan intensitas pantulan diffuser pada semua posisi sudut dan pada satu frekuensi yang diuji.

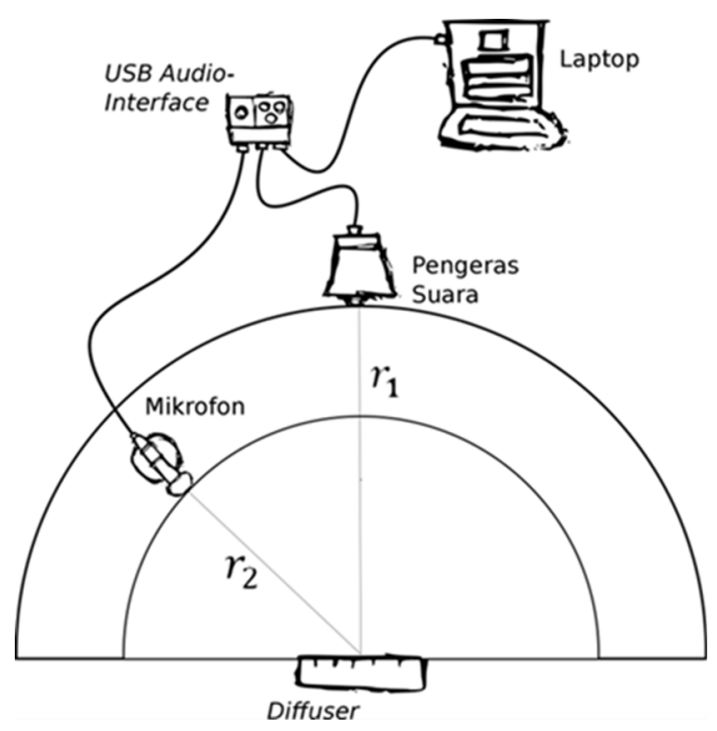

GAMBAR 1. Model Pengujian Diffuser.

Pada gambar 2 bagian E, grafik koefisien difusi diperoleh berdasarkan grafik respon polar pada semua frekuensi. Intensitas pantulan diffuser pada satu frekuensi dan pada satu posisi sudut dihitung koreksi berdasarkan jarak antara diffuser dengan mikrofon dan pengeras suara dengan menggunakan persamaan 1 dan 2 [4].

$$
\begin{aligned}
& L_{i}=L_{i}^{\prime}+\varepsilon 10 \log _{10}\left(\frac{r}{6.67}\right) \\
& r=\frac{2 \times r_{1} \times r_{2}}{\left(r_{1}+r_{2}\right)}
\end{aligned}
$$

Dimana, $\mathrm{L}_{\mathrm{i}}$ adalah tingkat intensitas suara pantulan yang terkoreksi di posisi ke-i (dalam satuan desibel); $L_{\mathrm{i}}^{\prime}$ adalah tingkat intensitas suara pantulan yang pengukuran (dan belum dikoreksi) di posisi ke-sekian (dalam satuan desibel); $\varepsilon$ adalah konstata untuk menentukan jenis pengujian yang dilakukan (tak bersatuan). $\varepsilon=1$ jika pengujian dilakukan dengan dua bidang (contoh pengujian dua bidang dapat dilihat pada Gambar 2.2. $\varepsilon=2$ jika pengujian dilakukan dengan tiga bidang (tiga dimensi). $\mathrm{r}$ adalah jarak antara mikrofon dan pengeras suara terhadap titik referensi (dalam satuan meter). $r_{1}$ adalah jarak antara pengeras suara terhadap titik referensi (dalam satuan meter). $r_{2}$ adalah adalah jarak antara mikrofon terhadap titik referensi (dalam satuan meter).i adalahurutan posisi. Koefisien difusi pada satu posisi pengeras suara diperoleh dengan menggunakan persamaan (3) [4].

$$
d_{\theta}=\frac{\left(\sum_{i=1}^{n} 10^{\frac{L_{i}}{10}}\right)^{2}-\sum_{i=1}^{n}\left(10^{\frac{L_{i}}{10}}\right)^{2}}{(n-1) \sum_{i=1}^{n}\left(10^{\frac{L_{i}}{10}}\right)^{2}}
$$


Dimana, $\mathrm{L}_{\mathrm{i}}$ adalah tingkat intensitas suara pantulan yang terkoreksi di posisi ke-i (dalam satuan desibel). $d_{\theta}$ adalah koefisien difusi (tak bersatuan). $\mathrm{n}$ adalah banyaknya pengukuran atau posisi titik uji (tak bersatuan). i adalah urutan posisi. Nilai koefisien difusi tiap frekuensi dapat digambarkan dalam bentuk grafik terhadap frekuensi. Gambar 2 bagian E merupakan contoh grafik koefisien difusi. Unjuk kerja sebuah diffuser dapat dilihat pada grafik koefisien difusi.

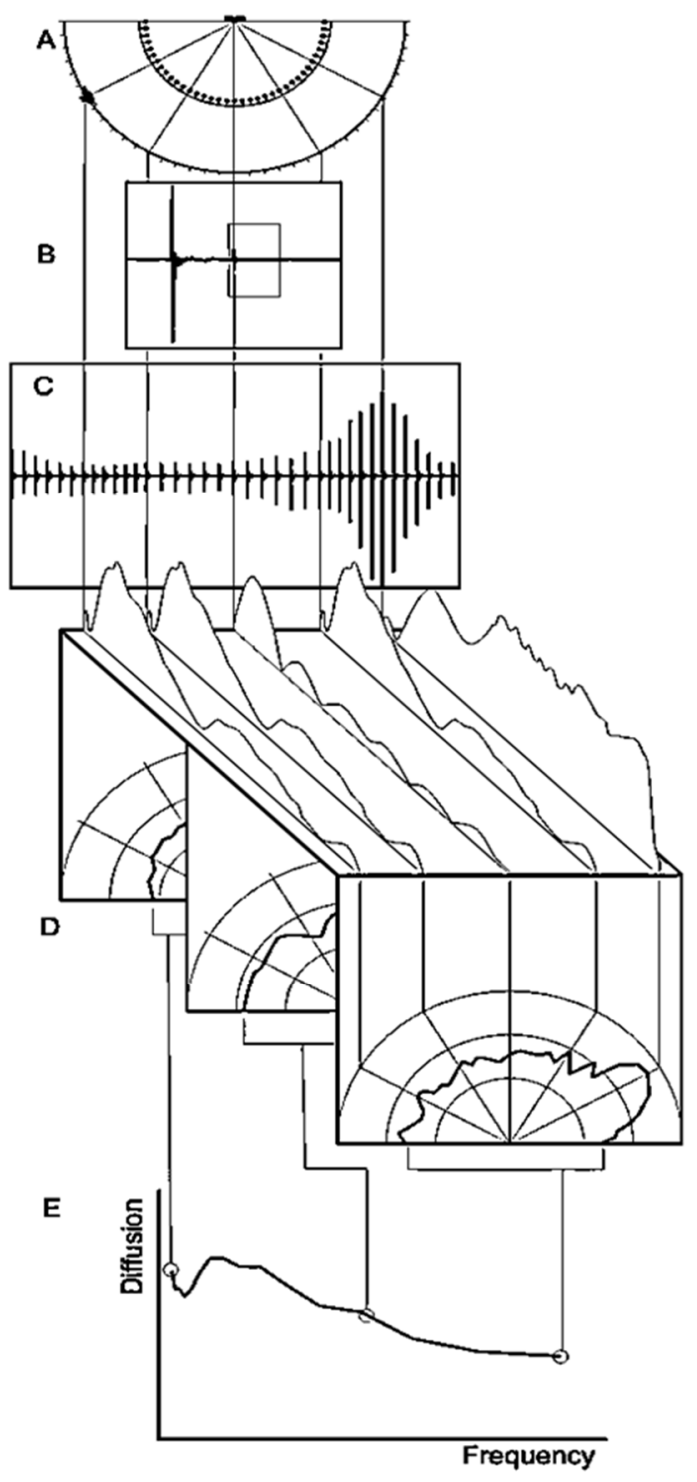

GAMBAR 2. Proses Pengolahan Pengukuran dari Perekaman Mikrofon hingga Grafik Koefisien Difusi [4].

\section{HASIL DAN PEMBAHASAN}

Pada bagian ini membahas hasil pengukuran dengan pendekatan grafik respon polar dan koefisien difusi.

\section{Grafik Respon Polar}

Gambar 3 merupakan pembahasan grafik respon polar pada frekuensi $800 \mathrm{~Hz}, 1000 \mathrm{~Hz}$, dan $1250 \mathrm{~Hz}$ pada semua diffuser yang diuji. Pada Gambar 3 (a), intensitas pantulan terbesar terletak pada sudut 0 derajat terhadap diffuser yang merupakan sudut posisi 'tembak' pengeras suara. Hal ini disebabkan karena frekuensi uji $800 \mathrm{~Hz}$ merupakan frekuensi di luar frekuensi desain diffuser, yakni frekuensi $1000 \mathrm{~Hz}$. Jika frekuensi uji di bawah frekuensi desain diffuser, maka diffuser berfungsi hanya sebagai permukaan pantul [1]. 
Jadi dapat disimpulkan bahwa karakteristik permukaan pantul adalah intensitas bunyi pantulan yang terbesar terletak pada sudut pantulnya. Gambar 3 (b) memiliki bentuk pola yang lebih merata ke pelbagai sudut. Hal ini disebabkan karena frekuensi $1000 \mathrm{~Hz}$ merupakan rentang frekuensi yang dirancang pada penelitian ini, yakni frekuensi $1000 \mathrm{~Hz}$ hingga frekuensi 3400 Hz. Gambar 3 (b) dan 3 (c) juga memiliki bentuk pola yang lebih merata ke pelbagai sudut. Hal ini disebabkan karena frekuensi $1250 \mathrm{~Hz}$ merupakan rentang frekuensi yang dirancang pada penelitian ini.
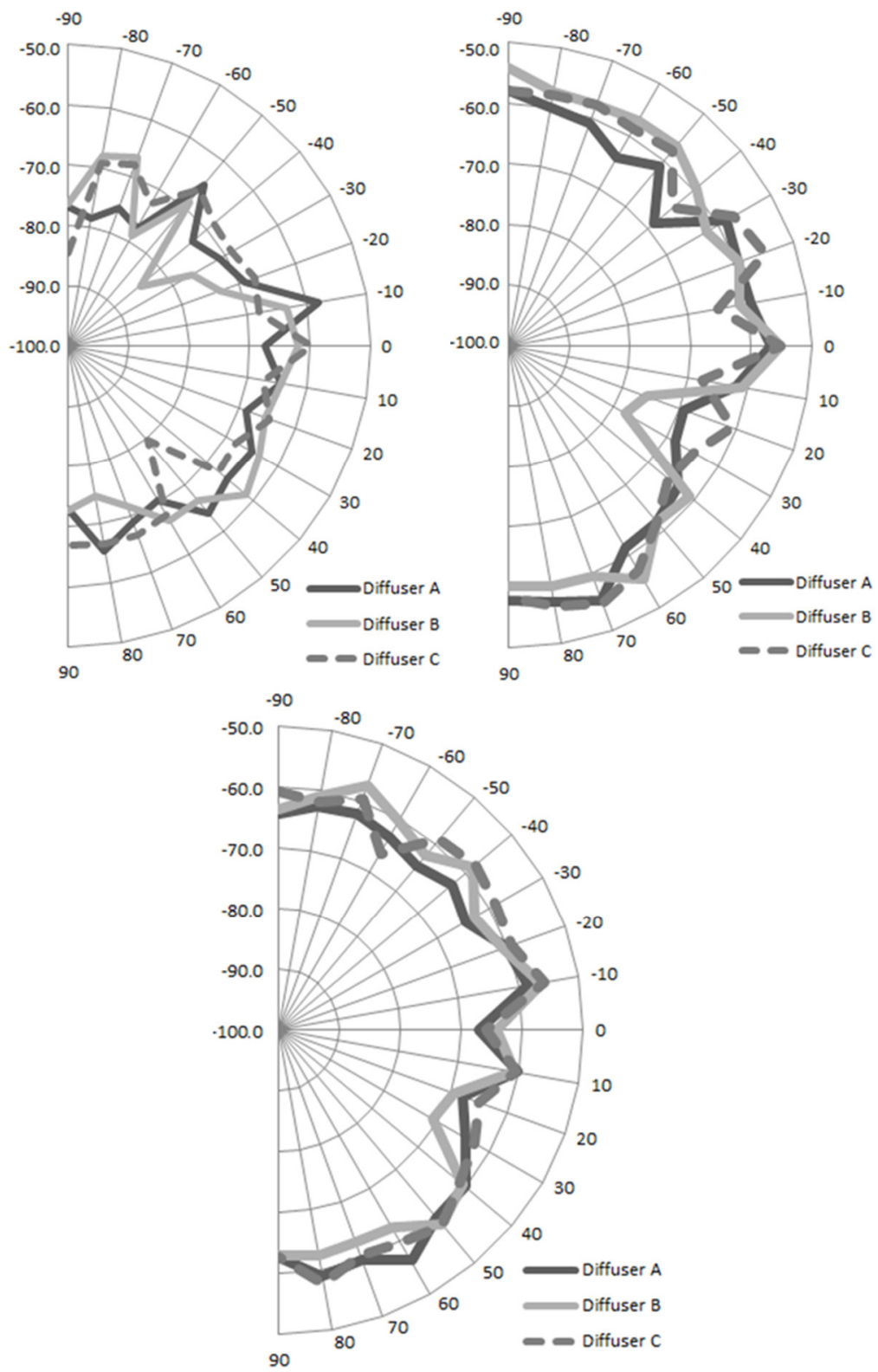

GAMBAR 3. Grafik respon polar frekuensi pada arah jarum jam: (a) $800 \mathrm{~Hz}$, (b) $1000 \mathrm{~Hz}$, dan (c) $1250 \mathrm{~Hz}$

\section{Koefisien Difusi}

Berikut ini adalah tabel koefisien difusi yang dapat dilihat pada tabel 3 dan grafik koefisien difusi yang dapat dilihat gambar 4 pada semua jenis diffuser yang diuji.

TABEL 3. Koefisien Difusi Hasil Perhitungan.

\begin{tabular}{|c|c|c|c|}
\hline \multirow{2}{*}{ Kolom ke- } & & $\mathbf{d 9 0}$ & \\
\cline { 2 - 4 } & Diffuser A & Diffuser B & Diffuser C \\
\hline 800 & 0.273 & 0.494 & 0.447 \\
\hline 1000 & 0.639 & 0.643 & 0.677 \\
\hline 1250 & 0.661 & 0.658 & 0.736 \\
\hline
\end{tabular}




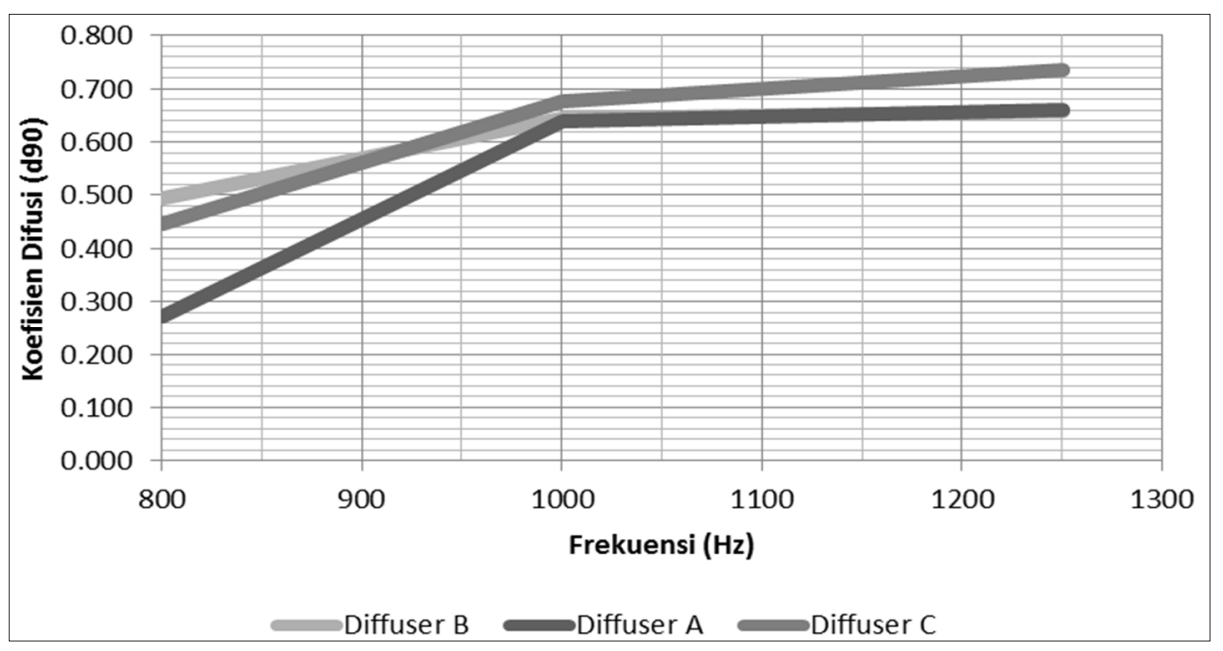

GAMBAR 4. Grafik Koefisien Difusi Hasil Perhitungan.

Pada gambar 3 dan tabel 3, terlihat perbedaan yang signifikan pada frekuensi $800 \mathrm{~Hz}, 1000 \mathrm{~Hz}$ dan $1250 \mathrm{~Hz}$. Pada frekuensi $800 \mathrm{~Hz}$, semua diffuser memiliki koefisien difusi dibawah 0.5. Frekuensi $800 \mathrm{~Hz}$ merupakan frekuensi di luar frekuensi desain diffuser. Sehingga semua diffuser hanya sebagai permukaan pantul.

Di samping itu, pada Gambar 4, terlihat perbedaan yang mencolok antara koefisien difusi pada diffuser A dengan B dan C. Koefisien difusi diffuser A pada frekuensi $800 \mathrm{~Hz}$ lebih rendah daripada koefisien difusi diffuser $\mathrm{B}$ dan $\mathrm{C}$ karena kayu pada diffuser $\mathrm{B}$ dan $\mathrm{C}$ lebih padat daripada diffuser C. Hal ini ditandai dengan densitas kayu-kayu yang diuji pada tabel 1. Densitas kayu diffuser B dan C lebih besar daripada diffuser A. Densitas kayu diffuser A lebih kecil sehingga diffuser A menyerap suara frekuensi lebih banyak dan pantulan yang diterima atau direkam oleh mikrofon lebih sedikit ketika diffuser dianggap sebagai permukaan pantul. Sedangkan densitas diffuser B dan C lebih besar sehingga diffuser B dan C memantulkan suara frekuensi $800 \mathrm{~Hz}$ searah sudut datang.

Pada frekuensi $1000 \mathrm{~Hz}$ dan $1250 \mathrm{~Hz}$, koefisien difusi semua diffuser di atas 0.5. Hal ini berarti semua diffuser dapat memantul dan dapat menyebarkan suara dengan baik. Hal ini disebabkan frekuensi $1000 \mathrm{~Hz}$ dan frekuensi $1250 \mathrm{~Hz}$ merupakan frekuensi desain diffuser. Di samping itu, koefisien difusi diffuser $\mathrm{C}$ lebih tinggi daripada diffuser lain yang diuji. Hal ini menandakan bahwa kayu diffuser $\mathrm{C}$ (yakni kayu kamper) merupakan kayu yang terbaik untuk dijadikan sebuah diffuser pada penelitian ini.

\section{KESIMPULAN}

Grafik respon polar memperlihatkan bahwa pada frekuensi uji $800 \mathrm{~Hz}$ diffuser yang dibuat tidak dapat menyebarkan suara pantulan. Namun diffuser dapat menyebarkan suara pantulan pada frekuensi $1000 \mathrm{~Hz}$ dan $1250 \mathrm{~Hz}$. Kayu kamper merupakan kayu yang terbaik untuk dijadikan sebuah diffuser karena memiliki koefisien difusi tertinggi yakni 0.677 pada frekuensi $1000 \mathrm{~Hz}$ dan 0.736 pada frekuensi $1250 \mathrm{~Hz}$.

Penelitian ini masih terdapat hal-hal yang perlu ditinjau untuk pengembangan penelitian jenis ini selanjutnya. Hal-hal tersebut antara lain. Titik sudut pengujian diffuser (dalam hal ini jumlah posisi mikrofon terhadap diffuser) sebaiknya diperbanyak sehingga koefisien difusi mendekati nilai yang realistis. Hal ini sejalan dengan banyaknya jumlah pengukuran, semakin banyak jumlah pengukuran, maka hasil pengukuran tersebut semakin baik. Jenis kayu yang diuji sebaiknya sesuai dengan kayu yang digunakan oleh insinyur akustik dalam merancang ruangan. Hal ini dilakukan supaya tujuan penelitian jenis ini sesuai dengan kebutuhan insinyur akustik. Pada penelitian ini, tidak dilakukan pengukuran kekasaran permukaan diffuser untuk mengetahui pengaruh kekasaran permukaan karena keterbatasan dalam penelitian. Namun, diperlukan pengukuran kekasaran permukaan atau perbanyakan sampel diffuser, antara diffuser 
yang diampelas dan diffuser yang tidak diampelas. Hal ini dilakukan untuk mengetahui koefisien difusi di antara dua jenis perlakuan tersebut.

\section{UCAPAN TERIMA KASIH}

Ucapan terima kasih ditujukan kepada Laboratorium Akustik dan Vibrasi Pusat Penelitian Metrologi Lembaga Ilmu Pengetahuan Indonesia yang telah memberikan kesempatan penulis untuk menguji diffuser di ruangan bebas gema.

\section{REFERENSI}

[1] Naziema Joeman, "Diffuser performance analysis by measured-based modelling," Delft University of Technology, Delft, 2005.

[2] Voichita Bucur, Acoustics of Wood, 2nd ed., R. Wimmer T. E. Timell, Ed. Berlin: Springer-Verlag, 2006.

[3] Mei-Huei Shen, Fang-Ming Lin, and Rong-Ping Lai, "Investigation on Sound Scattering Performances of Wooden and Bamboo Diffusers," in International Conference on Multimedia Technology (ICMT), Hangzhou, 2011, pp. 4478-4481.

[4] Audio Engineering Society, "AES-4id-2001: AES Information document for room acoustics and sound reinforcement systems - characterisation and measurement of surface scattering uniformity," 2001.

[5] The Wood Database. (2016, Januari) Light Red Meranti. [Online]. http://www.wooddatabase.com/lumber-identification/hardwoods/light-red-meranti/

[6] The Wood Database. (2016, Januari) Teak. [Online]. http://www.wooddatabase.com/lumber-identification/hardwoods/teak/

[7] The Wood Database. (2016, Januari) Camphor. [Online]. http://www.wooddatabase.com/lumber-identification/camphor/

[8] M.R. Monazzam, Y.W. Lam, Applied Acoustics 69, 93-109 (2008).

[9] Fang-Ming Lin, Pei-Yu Hong, Chia-Yen Lee, Applied Acoustics 71, 68-78 (2010).

[10] M.R. Monazzam, Y.W. Lam, Applied Acoustics 66, 709-730 (2005).

[11] Trevor J. Cox, Y.W. Lam, Applied Acoustics 41, 237-246 (1994).

[12] Samson Audio. (2003) Samson C02 Owners Manual. Document.

[13] LOUD Technologies Inc. (2015) CR3 \& CR4 Owners Manual Document. 